\title{
Tin oxide doped on activated dolomites as efficient catalyst for biodiesel production
}

\begin{abstract}
Activated dolomite (AD), was investigated as a promising heterogeneous catalyst for the production of biodiesel. $\mathrm{SnO} 2$ doped on activated dolomites catalyst (DSN) was synthesized through wet impregnation method and calcined at $500 \mathrm{C}$ for $3 \mathrm{~h}$ in air. The catalyst was then applied on biodiesel production via transesterification of palm cooking oil with methanol for required conditions (various time, oil to methanol ratio and amount of catalyst). X-ray Diffractometer (XRD), Brunauer-Emmet-Teller (BET) surface area, X-ray Fluoresence (XRF), Scanning Electron Microscopy (SEM) and Temperature Program Desorption (TPD) analysis were used to characterize the properties of the catalysts. Results showed that conversion of biodiesel by using DSN was higher (99.9\%) with lower optimum conditions i.e. 1:15 methanol to oil molar ratio, $1 \mathrm{wt}$. \% of catalyst amount and reaction time of $6 \mathrm{~h}$ at 65 C compared to AD (98.34\%) under higher conditions.
\end{abstract}

Keyword: Biodiesel; Dolomites; Heterogeneous catalyst; Palm oil; Tin oxide; Transesterification. 